\title{
Developing an intervention to equip nurses for acute life threatening events (ALTEs) in hospital: a phenomenological approach to healthcare research
}

\begin{abstract}
Objectives

To understand staff's experiences of acute life threatening events (ALTEs) in a pediatric hospital setting. These data will inform an intervention to equip nurses with clinical and emotional skills for dealing with ALTEs.
\end{abstract}

\section{Method}

A mixed design was used in the broader research program; this paper focuses on phenomenon-focused interviews analyzed using Interpretative Phenomenological Analysis (IPA).

\section{Results}

Emerging themes included staff's relationships with patients and the impact of personhood on their ability to perform competently in an emergency. More experienced nurses described 'automatic' competence generated through increased exposure to ALTEs and were able to recognize 'fumbling and shaking' as a normal stress response. Designating a role was significant to staff experience of effectiveness. Key to nurses' learning experience was reflection and identifying experiences as 'teachable moments'. Findings were considered alongside existing theories of self-efficacy, reflective thought and advocacy inquiry to create an experiential learning intervention involving a series of clinical and role-related scenarios.

\section{Conclusion}

Cite as: Hudson AP, Duncan HP, Pattison HM, Shaw RL. Developing an intervention to equip nurses for Acute Life Threatening Events (ALTEs) in hospital: A phenomenological approach to healthcare research. Health Psychology 2015;34(4):361-370. Available from:

http://dx.doi.org/10.1037/hea0000193. 
The phenomenological work facilitated an in-depth reading of experience. It accentuated the importance of exposure to ALTEs giving nurses experiential knowledge to prepare them for the impact of these events. Challenges included bracketing the personhood of child patients, shifting focus to clinical tasks during the pressured demands of managing an ALTE, normalizing the physiological stress response and the need for a forum and structure for reflection and learning. An intervention will be designed to provide experiential learning and encourage nurses to realize and benefit from their embodied knowledge.

\section{Keywords}

Acute life threatening event (ALTE); pediatric; phenomenology; healthcare intervention; simulation; reflection

\section{Acknowledgements}

Thanks go to the UK West Midlands Strategic Health Authority Nursing and Allied Health Clinical Research Fellowship which funded Adrienne Hudson to conduct this research as part of her doctoral thesis and to Birmingham Children's Hospital NHS Foundation Trust for hosting it. Thanks also to all the nurses and doctors who gave their time to provide a wealth of data; the insight gained from them was fundamental to this work.

Cite as: Hudson AP, Duncan HP, Pattison HM, Shaw RL. Developing an intervention to equip nurses for Acute Life Threatening Events (ALTEs) in hospital: A phenomenological approach to healthcare research. Health Psychology 2015;34(4):361-370. Available from: 


\section{Introduction}

An acute life threatening event (ALTE) has been defined as "an episode that is frightening to the observer [and in] some cases the observer fears that the infant had died" (NIH, 1986; p.1). An ALTE may manifest as cardiac or respiratory arrest, apnoea, choking, or marked change in color or muscle tone (NIH, 1986). The clinical outcomes of ALTEs are poor with less than half the patients' who suffer a cardiac arrest surviving and many more requiring prolonged hospitalization and support for neurological injury (Nadkarni et al., 2006; Tibballs et al., 2005; Young and Seidel, 1999).

Current mandatory training focusses on the clinical skills required to support patients' oxygenation and circulation. There is no discussion within Life Support Training to prepare staff for how they may feel during or after such an event (Resuscitation Council UK, 2013). As safety improves, nurses infrequently encounter ALTEs, so they haven't acquired an understanding of the personal impact of these events through repeated experience either.

ALTEs can contribute to the phenomenon of 'second victims' (Scott et al., 2009). Staff who lack appropriate skills to perform clinical tasks competently during an ALTE, or who are illequipped to deal emotionally with the impact of it may themselves, suffer. This can lead to staff burnout, increased absenteeism, anxiety and stress (McInnes and Bannister, 2005; Bailes, 2001; Coterill-Walker, 2000; Zigmond and Snaith, 1983). There is a paucity of research investigating the experience and psychological impact of dealing with ALTEs and no work identified in pediatric care (Hudson, 2014). Pups et al. (1997) explored nurses' experiences of caring for an adult who has an ALTE and found them to be experienced as demanding (especially when nurses knew the patient), well-controlled (due to good teamwork and expertise), ethically challenging (if nurses felt resuscitation should have ceased sooner), or as a learning experience (through observing others work). Following the ALTE, nurses Cite as: Hudson AP, Duncan HP, Pattison HM, Shaw RL. Developing an intervention to equip nurses for Acute Life Threatening Events (ALTEs) in hospital: A phenomenological approach to healthcare research. Health Psychology 2015;34(4):361-370. Available from: 
engaged in 'gallows humor' with colleagues and generally feelings were dictated by outcome, e.g. pride following survival and helplessness following death. Role allocation and the presence of experts were identified as features which may help prepare nurses to cope better with ALTEs.

Ambulance crews described dealing with incidents that involved children as amongst the most stressful events that they had to deal with. Calls to deal with cot death, injured children, situations where the child resembled a family member and situations where they had spent some time with the child and felt a connection with them were cited as being extremely stressful (Clohessy \& Ehlers, 1999; Halpern, Gurevich, Schwartz \& Brazeau, 2009).

There is, however, little literature on the specific experience of nurses who care for children in hospital which informs interventions to prepare nurses for the transition from playfully feeding a child in one moment and then doing firm and effective cardiac massage a moment later.

A systematic review identified debriefing only techniques that have been developed to support practitioners following a critical incident or emergency, e.g. Critical Incident Stress Management (Everly \& Mitchell, 1997; Leonhardt \& Vogt, 2006; Blacklock, 1998; Gamble, 1998) and no preparatory interventions to prepare nurses for ALTEs in pediatric settings (Hudson, 2014). Similarly, an international survey of practice to determine whether hospitals around the world had interventions or policies in place to prepare nurses for ALTEs in children identified Life Support or simulation training for clinical skills, post-event support and debriefing but none of the 44 hospitals surveyed offered preparatory skills training for dealing with the emotional and cognitive consequences of ALTEs (Hudson, 2014).

Cite as: Hudson AP, Duncan HP, Pattison HM, Shaw RL. Developing an intervention to equip nurses for Acute Life Threatening Events (ALTEs) in hospital: A phenomenological approach to healthcare research. Health Psychology 2015;34(4):361-370. Available from:

http://dx.doi.org/10.1037/hea0000193. 
The lack of evidence base for preparation confirmed the need for new empirical work to first describe and understand nurses' experiences of ALTEs in children and then to develop an intervention to better equip nurses with clinical and emotional skills to manage ALTEs inthe-moment and retrospectively.

\section{Method}

To obtain empirical evidence of nurses' experiences of ALTEs an interpretative phenomenological approach was adopted. Phenomenology is a school of thought which prioritizes the lifeworld, i.e. the context-specific, time-bound, spatial/geographic elements of experience that impact on sense-making and behaviour (Churchill \& Wertz, 2001). As such, it was an ideal approach to adopt for the exploration of staff's lived experience of the phenomenon of ALTEs. Furthermore, Patricia Benner's (1982) seminal work, From Novice to Expert, has taken this approach. She described the professional journey of a nurse using Dreyfus \& Dreyfus' (1986) model of skill acquisition: from novice, advanced beginner, competent, proficient, to expert. Benner adopted an interpretative phenomenological approach in her work to attempt to come to understand the 'preconscious' aspects of becoming an expert practitioner through narrative expression in research interviews and interpretative analysis.

This study aimed firstly to understand clinical staff's experiences of pediatric ALTEs and secondly, to use this insight to develop an experiential learning intervention to equip nurses clinically and emotionally for ALTEs. When an ALTE occurs, a specialist team comprised of nurses and doctors with varying levels of knowledge, experience and training attend.

Although the study aimed to develop a nursing intervention, by seeking accounts from both

Cite as: Hudson AP, Duncan HP, Pattison HM, Shaw RL. Developing an intervention to equip nurses for Acute Life Threatening Events (ALTEs) in hospital: A phenomenological approach to healthcare research. Health Psychology 2015;34(4):361-370. Available from:

http://dx.doi.org/10.1037/hea0000193. 
nurses and doctors we were able to gather a richer variety of data from clinicians with different levels of training and experience to better inform the intervention development.

\section{Participants}

Approvals were obtained to recruit participants from wards (excluding events that occurred in the emergency department, pediatric intensive care, and theatre) in a UK tertiary referral hospital with approximately 50,000 annual pediatric inpatient admissions. Nurses and doctors with varying levels of experience involved in ALTEs were invited to participate. Following an ALTE, the resuscitation training officer alerted the research team of staff involved, a participant information sheet was sent to the participants, and time was allowed for them to decide whether to take part. 24 of 26 participants who were identified, responded and gave consent to be contacted to organize a time for data collection. Participants were divided into four sub-groups: junior nurses with less than five years clinical experience (group 1); senior nurses with more than five years' clinical experience; junior doctors from pediatric specialisms without advanced airway management training (group 3) and senior doctors with advanced airway management training (group 4). A summary of the participants is provided in Table 1.

- Table 1 here-

\section{Data collection}

Individual semi-structured interviews were conducted by the first author usually in a private room near the ward in which the clinician worked. The interviewer was trained as a nurse and midwife and had been working in the capacity of research nurse for 9 years at the time of data collection. Following an initial question asking participants to describe the ALTE prompts such as, 'can you explain that more' or 'tell me more about that' were used to elicit further detail. Participants were encouraged to pause and think about their ALTE experience and to for Acute Life Threatening Events (ALTEs) in hospital: A phenomenological approach to healthcare research. Health Psychology 2015;34(4):361-370. Available from: 
reflect on how it made them feel. Interviews were usually conducted within a week of the event so it was fresh in their minds. Interviews were audio-recorded and transcribed verbatim.

\section{Ethics}

Ethical approval was granted prior to recruitment from the National Research Ethics Service (Ref. 10/H0408/66), Aston University Ethics Committee and the hospital Research and Development department. All participants were given pseudonyms and any information which threatened their anonymity was excluded from the transcript. Participants were informed they could withdraw their consent up to five days after the interview and have their data withdrawn from analysis, but none chose to do so.

\section{Data analysis}

Interpretative Phenomenological Analysis (IPA; Smith, Flowers \& Larkin, 2009) was used to analyze the data. The theoretical foundations of IPA are commensurate with interpretative phenomenology. It is an idiographic approach which examines in-depth individuals' subjective experiences and how they make sense of their personal and social world. The analysis was inductive; the generation of themes was led by participants' data rather than any predetermined expectations. Analysis proceeded on a case-by-case basis to maintain its idiographic commitment before conducting a cross-case analysis toward the end of the process (for details of the analytic procedure see Smith et al., 2009). Analysis was led by the first author and regular meetings of all authors were held to discuss initial themes, thematic groupings, and the cross-case analysis. In IPA the analyst is actively engaged in interpreting the data which requires a reflexive approach (Shaw, 2010). The lead analyst used a research diary to help identify preconceptions, articulate thoughts and feelings following interviews, 
and cross-check interpretations in the analysis to ensure they were rooted in the participants' accounts.

\section{Results}

Key themes developed using IPA include: 'personhood of patient and nurse', 'a designated role during resuscitation', 'clinical competence and confidence', 'misinterpreting the stress response', and 'sense-making and reflecting'. The significance of each theme is illustrated below with example data extracts.

\section{Personhood of patient and nurse}

The practice of pediatric nursing involves activities which are not purely the exercise of clinical skills; pediatric nurses may feed infants their bottles, help older children eat, bathe them, dress them, and play with them. When parents are absent, the nurse is often called upon to soothe and comfort the child. When parents are present, nurses often help parents care for their child especially when there is monitoring and treatment equipment. Relationships build between staff and parents, and children, which can impact on how nurses react during an ALTE.

“Umm I think it's just more the patient, I mean I've looked after Isabelle a lot, I've known her from a baby, I brought her up from PIC [Pediatric Intensive Care] after her first stage, I've admitted her for [cardiac] catheters [invasive cardiac procedure], discharged her when she's had catheters. Her Mum and Dad are lovely and I had quite a good relationship with her parents, so I think it was that and the fact of, of Dad, of seeing Dad and he was on his own, he was so scared to ring Mum 'cos he didn't want her to rush here and, and it was all of that together, it was all that really I think." (Sarah, junior nurse) 
Knowing the child and family over an extended period can make patients feel like "part of the family" (Margaret) which can blur the boundaries between personal and professional. While feeding a baby will look intently at the nurse, s/he may wrap her/his little finger around the nurse's finger accepting the essential nutrition with seemingly unconditional trust, thus creating a nurturing bond. This intimacy has a different quality to care provision in an adult setting and while it may create a feeling that is pseudo-familial, it brings with it the risk of the nurse experiencing a more marked emotional response to an ALTE.

"When Mum came to, I rang Mum and said I think you need to come to the ward she...um has become unsettled. And Mum came to the ward and she like came to the ward and was like "what have you done to my girl". Obviously I took that personally, as you do. But like when I spoke to her after and the girls spoke to her, she didn't mean as in "what have I done to her" [points to herself]." (Jessica, junior nurse)

Jessica's personal feelings were inextricably linked to her nursing practice which meant she took the mother's words as a personal attack. Following this interaction Jessica described feeling that she had let the mother down.

There is an assumption that knowing what to do comes naturally to healthcare professionals and when it doesn't, they risk perceiving themselves as inadequate. Focusing on the personhood of patients gels with the notion of holistic care and it was clear in nurses' accounts that they felt a close rapport with patients and families. Belinda described an ALTE of a patient she had cared for long-term over multiple admissions which shocked her as his personhood diminished.

"The one thing I remember thinking was it looked like they were going to break his ribs they were sort of doing it [chest compressions] quite hard. [..] Because Zahid, by Cite as: Hudson AP, Duncan HP, Pattison HM, Shaw RL. Developing an intervention to equip nurses for Acute Life Threatening Events (ALTEs) in hospital: A phenomenological approach to healthcare research. Health Psychology 2015;34(4):361-370. Available from: 
this point he'd been intubated and was totally unconscious, he was really floppy and I could just sort of remember his head bouncing off the bed and it...it was just really horrible to watch, I mean I know I am going to see it again at some point, but I just hope it's, well I hope it's not like that [..] I was quite shocked by that if I am honest." (Belinda, junior nurse)

Seeing Zahid as an object, being 'done to', was disturbing for Belinda and this was quite common among junior staff who knew the patients before their ALTE. Belinda was fixated on Zahid as a person, which prevented her from adopting the more automatic clinical response of the more senior staff. Indeed, one of Belinda's colleagues described her as "a rabbit in the headlights" (Laura), "seemingly frozen, evidently in shock". Another account from Daniel, a very experienced senior doctor, demonstrated that even though he was able to adopt the automatic, clinically focused response of an expert - often achieved by dehumanizing patients - their personhood still sneaks through.

"While we were doing CPR I am getting adrenalin and bag and masking this child certainly... [draws in breath] it was breathing which hasn't happened to me very often, I, he was certainly fighting for his own life and then you have to put a tube down and paralyze and ventilate them." (Daniel, senior doctor)

Daniel's initial use of "it" is characteristic of someone viewing the patient as an inanimate object during an ALTE to get the job done. He then paused, drew breath, and switched to "he" signifying his remembered realization that he was treating a little boy. Later Daniel emphasized how unusual this ALTE was because the patient was conscious and may be in need of treatment for pain or sedation - again reminding him that it was a person, not just a for Acute Life Threatening Events (ALTEs) in hospital: A phenomenological approach to healthcare research. Health Psychology 2015;34(4):361-370. Available from: 
body he was treating. His initial response shows a potential coping strategy that experienced staff use to prioritize the clinical lifesaving skills above the cognitive emotional experience.

\section{A designated role during resuscitation}

The previous themes provided useful context to junior nurses' relationships with patients and parents and their struggle to dissociate the personal and professional. This theme describes how this task becomes more achievable when assigned a designated role during the ALTE. Rachael described being unable to prevent herself from prioritizing the patient's personhood and how that upset her once her initial role was complete.

“After I'd done the chest compressions it's like you take a step back and you think oh, you sort of take in what's going on, but I think if I'd had something, I'm not saying something to do like I was bored, but if I had something to get on with I think umm...I don't think those feelings would have...I wouldn't have been feeling how I was feeling. I wouldn't have had time to think." (Rachael, junior nurse)

Laura's account, as a responding doctor who had received training, demonstrates how repeated exposure to ALTEs enabled her to react almost automatically and take on a more global overview of the situation. She was also aware that junior nurses saw her as a role model and seemed to feel more secure when being told what to do.

"For me, yeah I think it was training and knowing what to do, knowing what my role was. I think, you turn up to an arrest and, I know... so many people have said it, that they feel better when there is somebody in charge who tells them what to do. So, I think if they know what their role is by...scenario training, I am not talking about psychological preparation, but I know that scenario training allows them to deal with 
it better. [..] It is almost like actions, sort of stops you feeling the emotion, so you stop thinking and you start doing." (Laura, consultant/specialist registrar)

As a doctor with specialized training, Laura was able to identify the link between exposure and clinical competence and saw the importance of being given a designated role. Charlotte, also a doctor, emphasized the significance of focusing on the clinical as a way of separating out the person.

"In acute situations you need to detach because if you don't that's when all the emotions come in and you can't get on with the A [airway], B [breathing], C [circulation], and D [disability] because you're thinking about everything else and that's I know that's what I guess I'm particularly good at, it's just the fact I don't, I stop seeing Mum, I stop seeing Dad, and I stop seeing the baby that I might have cooed at this morning and it's just "this is what I have to do"." (Charlotte, consultant/specialist registrar)

Here Charlotte demonstrated her ability to bracket off any feelings she may have otherwise felt because she was consumed by the clinical task at hand. As well as being able to detach from the personhood of the patient, the nurses expressed the need to feel confident in the clinical task they were asked to perform: "I'd done that before, I kind of felt more comfortable in that" (Kelly); "I was quite happy to do the bits that I knew I could do" (Carol). There was agreement among junior and senior nurses about the need for a designated role and to feel competent in fulfilling the associated clinical task. The designated role helped the staff to feel like they had contributed to treating the patient. Interestingly despite being the person most informed about the patient, most nurses hadn't considered the role of bedside nurse as a valid one during the resuscitation.

Cite as: Hudson AP, Duncan HP, Pattison HM, Shaw RL. Developing an intervention to equip nurses for Acute Life Threatening Events (ALTEs) in hospital: A phenomenological approach to healthcare research. Health Psychology 2015;34(4):361-370. Available from: 


\section{Clinical confidence and competence}

Some nurses assumed that clinical skills should come naturally to a nurse and that any failings were due to inadequacies as a healthcare professional rather than due to external factors, such as lack of clinical training or the physical stress response. However, not all clinical interventions required during an ALTE are taught explicitly in nursing training. For example, the skills required when allocated to support the parents during an ALTE (explaining what has happened to their child, what treatment is being provided and supporting them emotionally) is not a role that is taught during nursing training. It was interesting therefore that the assumption of 'natural' clinical competence remained. Participants talked about clinical confidence and competence almost interchangeably giving the impression they were interdependent. When asked what led to being more confident, Emma states:

"Learning more, so knowing more. So, since then I've done my APLS [Advanced Pediatric Life Support training] and we're always being updated on PILS [Pediatric Immediate Life Support] and things. So I feel more comfortable, if that's the right word, in those situations and feel more confident in my abilities and...the more things you see, the more you become acquainted with different situations. So, every arrest is not the same, but I feel the more you see, the more you do, and the more involved you get, the better you are at dealing with it, and being useful. [..] because you're able to do more and participate more, one you haven't got time to get emotional, and feel...you're not doing anything, because you are doing stuff. Plus you feel like you're contributing. So you feel like you've actually made a difference. So I think that's one of the reasons why my feelings have changed as I have changed and learnt more." (Emma, senior nurse) 
Repeated exposure to ALTEs and practice performing different tasks required in different situations enabled Emma to learn appropriate skills and to develop confidence in her ability. Coupled with a positive outcome (the patient survived), this consolidated Emma's view of herself as a competent clinician. By contrast, Rachael described feeling incompetent which dented her confidence. She was asked to draw up medication, something in which nurses are not always trained, and felt compelled to pass it on to another member of ALTE team: "I couldn't say “I'm sorry I don't know how to do this". I just sort of handed it to the bed manager." (Rachael). This was an uncomfortable experience for Rachael compared to the pride evident in Emma's account of having "actually made a difference". ALTEs were experienced positively or negatively in relation to their learning experience, as described above, or they were bound up within the outcome for the patient. In Rachael's ALTE, the patient did not survive which made her question whether anything positive, in terms of a learning experience, could be taken from it: "when you've had a negative outcome it's hard to be positive about any situation. Yeah it did knock my confidence a bit." (Rachael).

Charlotte offered a different perspective which advocated dissociating between the patient outcome and her own outcome in terms of competence as a clinician.

"When I was a medical student and I shadowed senior people, I think I was always put into the mindset of "this is what happens and you have to deal with it". As long as you know your A, B, C, D it'll be okay, even if the outcome is not okay you will know that you have done something. [..] You can't help save everyone and you know it, and you know that. But you might, if you did this, this, and this. [..] That makes you think, well it is worth knowing what to do, and it is worth doing it." (Charlotte, consultant/specialist registrar)

Cite as: Hudson AP, Duncan HP, Pattison HM, Shaw RL. Developing an intervention to equip nurses for Acute Life Threatening Events (ALTEs) in hospital: A phenomenological approach to healthcare research. Health Psychology 2015;34(4):361-370. Available from: 
The frank approach Charlotte learned in medical training sets up a realistic expectation of the clinical environment. Similar types of psychological preparation were not found in the nurses' accounts; there were no stories of prior conversations during training or their day-today practice where they were reminded of ALTEs and the likelihood that some would inevitably have negative outcomes. Feeling prepared enabled the doctors in the sample to hone their clinical skills to ensure when they found themselves in an ALTE situation they knew what to do. Nevertheless, there were commonalities between the senior doctors' and nurses' accounts in terms of being focused on a particular role or task during resuscitation. Knowing they had done their best to save the child's life enabled the senior staff to offset a negative patient outcome.

\section{Misinterpretation of the stress response}

On top of the emotional response some nurses reported, was the physical impact of shock.

Carol, a junior nurse, hadn't been involved in many ALTEs and described her sense of "just sort of going to pot straight away":

"Well, I just - it was very, very quick so... well just sort of panicked you know, you go kind of a bit numb if I'm quite honest. Yeah, your hands start shaking and stuff like that and I just thought "oh god his poor mother"." (Carol, junior nurse)

It is not clear from Carol's account whether she was aware that her shaking was a physical manifestation of shock. By describing it as "panicking" and "going to pot" she attributed agency to her actions, owning them as something for which she was to blame. Embedded within this was self-criticism. Rachael recognized her shock, but still felt it personally as a failing in her ability.

Cite as: Hudson AP, Duncan HP, Pattison HM, Shaw RL. Developing an intervention to equip nurses for Acute Life Threatening Events (ALTEs) in hospital: A phenomenological approach to healthcare research. Health Psychology 2015;34(4):361-370. Available from: 
"I thought to myself what do I do now [..] I couldn't write because I was shaking, I was thinking, I must have been in shock, I must have been. Umm I tried to write on the PEWS chart [observation chart] to get some documentation and I couldn't even do that." (Rachael, junior nurse)

The more experienced staff had developed mechanisms to recognize and manage the shock response. Margaret had been nursing for over 20 years and had been involved in many ALTEs during that time. Instead of assuming self-criticism or imbuing a level of performance within the physical shock response, Margaret read it as a normal reaction and had developed a way of postponing it. She described it as automatic and clapped her hands: "It is just automatic, I don't think, it was just like [claps her hands] get this, this and this." It was as if the physical act of clapping her hands stopped her from shaking and enabled her to focus on the task at hand. Once the job was done, she allowed her body to respond.

"I still have that sort of feeling, of where, I don't know about anybody else, but I can sort of cut myself off, while I'm doing the resuscitation, but post resuscitation, feel very shaky and emotional, not, not crying but just shaky." (Margaret, senior nurse)

Similarly, Charlotte described going "into robot mode" during an ALTE. However, Charlotte was able to channel her embodied shock response to the ALTE situation and experienced it positively as an "adrenaline buzz". Both Margaret and Charlotte had experienced many ALTEs and were able to manage their shock through repeated exposures; they had learned to acknowledge and take charge of their bodily responses to prevent them disrupting their clinical abilities. The description of this as "automatic" is counterintuitive and potentially unhelpful for newly qualified nurses. It could be perceived as natural and something that nurses should be able to do without this being addressed in their training simply because they for Acute Life Threatening Events (ALTEs) in hospital: A phenomenological approach to healthcare research. Health Psychology 2015;34(4):361-370. Available from: 
are nurses. Instead, Charlotte and Margaret described how they had reflected on their experience following ALTEs which had enabled them to crystalize their feelings and learn how their body responded in order to identify techniques to work through it.

\section{Sense-making and reflecting}

Taking the time to talk through and reflect on ALTE experiences was identified as central in many participants' accounts. Sarah felt a need for a more formalized process of reflection following an ALTE which would help consolidate her learning.

“So you just don't talk, unless you choose to talk to somebody about it, when you're at work, it's just not spoken about. And I think that can be quite difficult, 'cos I think even, just talking through these are the obs I did, this is what I wrote on my PEWS chart or this is what I take to the doctors. Or, just go through it like that, it helps you process it in your head and realize that you did a good job, or you did a good job but this is what you could do next time." (Sarah, junior nurse)

Identifying teachable moments in this way would make good use of nurses' experiential knowledge and help develop their clinical competence by increasing their repertoire of things that work well during an ALTE. The absence of formalized reflection at work meant nurses attempted to find confidantes outside of work to fulfil that role. Rachael realized her need to talk following her ALTE experience as she struggled to make sense of what had happened.

"I think I'd have wanted to talk about it straight away. Yeah and then it's hard when you go - I mean I live on my own, so it's hard when you go home, 'cos you've still got no-one to talk to and then you can't call your mum, because they don't, they don't quite understand, and yeah, and then the only people you can talk to are the girls on 
the ward which is nice, it's still nice. Yeah, but I think it's, it's when I went home I thought, "bloody hell!" [laughs]" (Rachael, junior nurse)

Being forced to depend on people outside of work is unacceptable and works to blur the boundaries between professional and personal. It also further corroborates the misconception that nurses should know intuitively how to act during ALTEs and how to deal with them both emotionally and in terms of translating them into a learning experience. Emma, a more senior nurse, described the lack of formalized reflection from a different perspective. She felt that as a senior nurse she was expected to know how to support more junior staff following ALTEs despite having had no training in how to do it.

"We just do it from experience, you just make it up as you go along really [laughs].

So maybe to have something, just like some sort of, I know we have lectures on communication and things like that, but just something to...that I could theoretically draw on which would help you to support people better. Sometimes I think I'm supporting someone brilliantly, their feelings might be completely different so just to know what to pick up on, what questions to ask the person, just some, something formal to guide." (Emma, senior nurse)

Just as nurses were expected to know intuitively how to deal with ALTEs, Emma's account illustrated a feeling that providing support was also something that just comes naturally to nurses, which of course is not always the case. The problem Emma identified was the lack of forum or structure to enable nurses to provide feedback about whether the support was appropriate or helpful. Instead of assuming intuitive knowledge these accounts demonstrated a need to make explicit the sense-making processes in which nurses must engage following an ALTE in order to learn from it and to develop professionally. Furthermore, there is a need Cite as: Hudson AP, Duncan HP, Pattison HM, Shaw RL. Developing an intervention to equip nurses for Acute Life Threatening Events (ALTEs) in hospital: A phenomenological approach to healthcare research. Health Psychology 2015;34(4):361-370. Available from: 
to formalize this reflection process to ensure feedback is possible and that support provided is appropriate.

\section{Synthesizing findings with theory to inform intervention development}

The Medical Research Council's guidance for developing complex interventions was used as a framework in this study (Craig et al. 2008). Intervention development is described as an iterative process which foregrounds the need to establish the evidence-base and to identify theoretical evidence. Theory is needed to postulate how the intervention will work, i.e. the mechanism by which change will occur (Michie and Abraham, 2004). Due to a lack of existing published evidence, it was necessary to generate new empirical data. Findings from the interviews were considered alongside existing theoretical evidence to inform the development of the intervention. This section will outline the synthesis of this evidence with theoretical evidence which was used to inform the intervention design.

A systematic literature review identified papers detailing relevant theory (Hudson, 2014). These were consulted to identify theoretical constructs which might represent aspects of nurses' cognitions and emotional responses to events that could be modifiable in an intervention. Changing cognitions and emotions should lead ultimately to changing behaviors including the performance of clinical skills in an ALTE and use of coping mechanism e.g. absenteeism (Pines and Maslach 1978; Maslach and Jackson 1980; Schaufeli, Salanova et al. 2002; Parker and Kulik 1995; Crabbe, Bowley et al. 2004; Mukherjee, Beresford et al. 2009). The relevant theories identified are summarized and mapped onto the empirical findings to describe the elements of the intervention developed in Table 2.

\section{- $\quad$ Table 2 here -}

Self-efficacy is a construct from Social Cognitive Theory focusing on confidence; it is an individual's belief in their ability to perform a specific behavior or task. Bandura (1977) Cite as: Hudson AP, Duncan HP, Pattison HM, Shaw RL. Developing an intervention to equip nurses for Acute Life Threatening Events (ALTEs) in hospital: A phenomenological approach to healthcare research. Health Psychology 2015;34(4):361-370. Available from: 
identified four techniques to change behavior through boosting an individual's self-efficacy: mastery experiences or performance accomplishments; modelling or vicarious experiences; verbal persuasion; and physiologically compatible experiences. The techniques described map closely onto the IPA themes: modelling or vicarious experiences would provide the opportunity to develop clinical competence and confidence; the need for a designated role and opportunity to practice that maps onto mastery experience or performance accomplishments; participants' misinterpretation of the stress response could be dealt with by providing physiologically compatible experiences in the intervention.

Reflection (or reflective thought) is a key component in Kolb's (1984) Adult Learning Theory. Reflective thought is defined as involving the following processes: developing a sense of the problem; enriching the sense with relevant observations; developing conclusions or a plan for change; and testing those conclusion or plans in practice Dewey (1933). Having a designated role during resuscitation would facilitate the process of developing a sense of the problem and enriching that sense with relevant observations. In order to develop a conclusion or a plan for a change, some sense-making and reflection would be required; indeed, each element of Dewey's reflective thought maps is represented in the theme, sensemaking and reflection.

Advocacy Inquiry (AI; Rudolph et al., 2006) is a technique that has been described as feedback with good judgment. It is based on two theories of action: espoused theory (what people say they will do and why) and theory in use (what they actually do and why). Argyris and Schön (1978) argue that people have tacit mental maps with regard to how to plan, implement, act and review their actions in situations. Fundamental to the theory is that, in order to develop or change behavior and psychological responses to situations, a person needs for Acute Life Threatening Events (ALTEs) in hospital: A phenomenological approach to healthcare research. Health Psychology 2015;34(4):361-370. Available from: 
to reflect on and make sense of their behavior or response in a contextualized way. The technique pairs advocacy (here an assertion or observation) with inquiry (questioning) to create a conversation focused on the event which may elicit the participant's cognitive schema. Using the advocacy-inquiry model demands conscious sense-making and reflection focused around the event; it has been developed to provide a structured, non-judgmental way of changing behavior so fits with this key finding in the IPA data.

Following this theoretical review it became clear that a number of distinct elements were required to create an intervention that could change nurses' target behaviors, i.e. to address the clinical skills required and the emotional reactions leading up to, during and after an ALTE. The mechanisms through which these behaviors may be modified were identified as: exposure, witnessing, experience, reflection, and consolidation (see Table 2). The focus on learning-by-doing demanded a practical intervention which led to the selection of simulation as the mode of delivery. A number of scenarios were developed to provide opportunities for nurses to practice a range of skills. The strong reflective element required a structured and supportive approach to ensure a safe space to think aloud and discuss the scenarios with trained expert clinicians to consolidate the learning and better equip nurses for dealing with ALTEs both clinically and emotionally in-the-moment and following it.

\section{Discussion}

Phenomenological psychology follows Husserl's call to return 'to the things themselves', i.e. everyday interactions, encounters or moments in life that make up our experience in order to understand human experience (Smith et al., 2009). The individual interviews enabled participants to describe their experience in depth and gave them a forum in which to reflect upon and make sense of their ALTE experiences. During data generation, participants were invited to pause and reflect, to think about and almost relive their ALTE experiences, and to Cite as: Hudson AP, Duncan HP, Pattison HM, Shaw RL. Developing an intervention to equip nurses for Acute Life Threatening Events (ALTEs) in hospital: A phenomenological approach to healthcare research. Health Psychology 2015;34(4):361-370. Available from: 
identify how they felt both during and after the ALTE. By using IPA, the analysis also involved a great deal of reflective and interpretative work; it evoked a double hermeneutic, i.e. the participants made sense of their experience by recounting it in the interview, and the analyst made sense of participants trying to make sense of their experience in the analysis (Smith et al., 2009).

Central to this work is language, both in terms of taking an interpretative phenomenological approach and in relation to the key findings centering on reflection and sense-making. It is through language that the rich textures of the participants' experiences can be accessed, expressed and shared (Willis, 2004). Galvin and Todres (2011) describe an aesthetic phenomenology, where the rich textures of experience can be evoked through language. We found that by engaging in event-focused reflective practice - by talking things through nurses were able to develop an embodied relational understanding of ALTEs that could be taken forward to future experiences (Finlay, 2008; Galvin \& Todres, 2011; Rees, 2013). Embodied knowledge was found to be central to participants' accounts and will influence the intervention development in the shape of mastery experiences, physiologically compatible experiences, reflective thought, and AI. Explicit knowledge ('knowing that') is accessible to the conscious mind and can be expressed in language quite easily (Bunge and Ardila, 1987; Pena, 2010). A novice may be able to demonstrate 'classroom' knowledge but still may struggle in a real life clinical situation. Implicit or tacit knowledge ('knowing how') is acquired through a combination of education, experience and relational understanding. Relational understanding requires enactive mastery and reflection. Expressing this knowledge in a formalized way is challenging (Heiberg Engel, 2008; Pena, 2010). This is the sort of knowledge experienced by nurses and doctors described as 'automatic'; knowledge that has been built up through firsthand experiences of ALTEs and reflecting on their meaning. Rather for Acute Life Threatening Events (ALTEs) in hospital: A phenomenological approach to healthcare research. Health Psychology 2015;34(4):361-370. Available from: 
than describing this knowledge as automatic, which implies a non-reflective approach, Carraccio et al. (2008) propose that experts are indeed reflective and intuitive; experts are able to self-assess, self-regulate, and reflect whilst in action (in-the-moment) and reflect back on their actions afterwards. This is consistent with the empirical findings reported here. As proposed by Dreyfus and Dreyfus (Dreyfus and Dreyfus 1986; Dreyfus, 1982), the analysis presented found that expert practitioners were able to 'pattern match' based on previous experience which enabled them to focus in on the problem seemingly without conscious thought. When approaching the feedback and debriefing structure it will be important to invite the intuitive reflections of the more experienced to help the less experienced practitioners understand the commonality and give language to their emotions and cognitions.

There is a wealth of literature around this topic including:

- $\quad$ Resuscitation guidance [Resus Council UK] for clinical skills, equipment and team processes. These are the standards for clinical care and they are reflected in the mandatory Life Support training for all healthcare workers.

- $\quad$ Crew-resource management and human factors in emergency teams which is concerned with the cognitive and interpersonal skills needed to effectively manage a teambased, high-risk activity (Brady, Muething, Kotagal, Ashby, Gallagher, Hall, Goodfriend, White, M. Bracke, DeCastro, Geiser, Simon, Tucker, Olivea, Conway \& Wheeler, 2013). - $\quad$ Prevention and reduction of occupational stress in healthcare is better maintained following both person- and organisation-level interventions (Awa, Plaumann \& Walter, 2010; van Wyk \& Pillay-Van Wyk, 2010).

Cite as: Hudson AP, Duncan HP, Pattison HM, Shaw RL. Developing an intervention to equip nurses for Acute Life Threatening Events (ALTEs) in hospital: A phenomenological approach to healthcare research. Health Psychology 2015;34(4):361-370. Available from:

http://dx.doi.org/10.1037/hea0000193. 
- $\quad$ Debrief alone may be insufficient and potentially dangerous suggesting the need for preparation (Rose, Bisson, Churchill, \& Wessel, 2002; van Emmerik, Kamphuis, Hulsbosch, \& Emmelkamp, 2002; Arendt \& Elklit, 2001).

- $\quad$ Caring for children with special needs is stressful (Ford \& Turner 2001).

However, none of these studies nor the systematic literature review (Everly \& Mitchell, 1997; Leonhardt \& Vogt, 2006; Blacklock, 1998; Gamble, 1998) nor the international survey of practice identified techniques that have been developed to prepare nurses for ALTEs in pediatric settings for dealing with the emotional and cognitive consequences of ALTEs (Hudson, 2014).

\section{Limitations}

Qualitative research is context-specific and grounded in the experience of its participants. This enables the investigation of experiences in-depth, but it also has limitations. Further research in similar pediatric settings and in adult settings in other areas of the UK and overseas would add validity to the findings of the current study because it is not possible to establish from the current findings whether they are generalizable to other settings. One issue is that those who volunteered may have been more confident in their dealings with ALTEs or had more positive experiences and therefore been more willing to participate; participation bias is always a risk regardless of the methodology. Furthermore, some may have been reluctant to disclose their experiences, especially those of distress, because they have been socialized to maintain a stoic, professional stance (Rees, 2013). Combatting this issue in research resonates with the issue of 'normalizing' reflective practice. It is hoped that this kind of intervention will help foster a culture which encourages open discussion of challenging clinical scenarios and therefore consolidates the learning process. Cite as: Hudson AP, Duncan HP, Pattison HM, Shaw RL. Developing an intervention to equip nurses for Acute Life Threatening Events (ALTEs) in hospital: A phenomenological approach to healthcare research. Health Psychology 2015;34(4):361-370. Available from: 
Despite these limitations, this research has delivered depth rather than breadth which facilitates 'vertical' rather than 'horizontal' generalization (Yardley, 2000). Representative samples enable horizontal generalization across the population; idiographic studies, such as this one, enable conceptual generalization, i.e. generalization of ideas. The synthesis of empirical findings with theoretical evidence in this study demonstrates that similar work in other settings has indeed reported similar findings, thus corroborating the results presented here. However, it is important for health psychology to retain a both/and approach to applied research; we need both a nomothetic (population level) analysis and an idiographic analysis in order to make sense of the full picture (Smith and Eatough, 2012). Indeed, the next step in this research is to test the effectiveness of the intervention using quantitative measures.

\section{Conclusion}

This paper has reported the phenomenological analysis of interviews with nurses and doctors about their experiences of ALTEs. It used those experiential data, synthesized with relevant theories to develop a healthcare intervention to equip nurses for dealing with ALTEs in hospital. The phenomenological work facilitated an in-depth, experience-close reading of nurses' encounters with ALTEs. It accentuated the importance of exposure to ALTEs giving nurses experiential knowledge.

This new empirical data will inform the design and testing of an intervention to better prepare nurses for their experiences in caring for a child who suffers an ALTE. Specifically, the intervention will prepare nurses to:

- Prioritize clinical skills and treatment during resuscitation

- Train for and take up a designated role to feel effective

Cite as: Hudson AP, Duncan HP, Pattison HM, Shaw RL. Developing an intervention to equip nurses for Acute Life Threatening Events (ALTEs) in hospital: A phenomenological approach to healthcare research. Health Psychology 2015;34(4):361-370. Available from: 
- Take up or designate the role of bedside nurse with the most up to date and relevant information

- Take on tasks such as documentation or 'scribe' and drawing up medicines under time pressure need to be learned and practiced

- Experience of the physical stress response such as shaking, a feeling of panic or freezing

- Recognize the emotional impact of knowing and feeling emotionally attached to the child and parents

- Train for the emotional and cognitive impact through repeated simulated experiences

- Role-model, enabling nurses to learn-by-doing during training and real events

- Gain the knowledge that the physical and emotional effects are normal, common to all and the personal impact reduces with experience

- Separate one's performance from the outcome of resuscitation

- Recognize the need to talk about the event to make sense of it

- Recognize the need to reflect and learn both personally and with the team

- Develop a formal structure for review and debrief

An intervention will be designed to incorporate these aspects into experiential learning and encourage nurses to recognize and build on their embodied knowledge. The aim will be to boost their perception of competence, confidence, self-efficacy and performance and to measure the impact of the intervention on stress, burnout, absenteeism and staff attrition.

\section{References}

Arendt, M., \& Elklit, A. (2001). Effectiveness of psychological debriefing. Acta Psychiatrica Scandinavia, 104(6), 423-437. 
Argyris, C., Schön, D.A. 1978. Organizational Learning: a Theory of Action Perspective.

Reading, Mass.: Addison-Wesley. ISBN 0-201-00174-8.

Awa, W.L., Plaumann, M., \& Walter, U. (2010). Burnout prevention: a review of intervention programs. Patient Education \& Counseling, 78(2), 184-490.

Bailes, G. (2001). Critical incident management. Nursing Times, 97(25), 40.

Bandura, A. (1986). Social foundations of thought and action: a social cognitive theory.

Englewood Cliffs, NJ: Prentice-Hall.

Bandura, A. (1977). Self-efficacy: Toward a Unifying Theory of Behavioral Change. Psychological Review, 84(2), 191-215.

Benner, P. (2001). From novice to expert: Excellence and power in clinical nursing practice. New Jersey: Prentice Hall Health.

Blacklock, E. (1998). Workplace stress: a hospital team approach. Professional Nurse, 13(11), 744-747.

Brady, P.W., Muething, W., Kotagal, U., Ashby, M., Gallagher, R., Hall, D., Goodfriend, M., White, C., Bracke, T.M., DeCastro, V., Geiser, M., Simon, J., Tucker, K.M., Olivea, J., Conway. P.H., \& Wheeler, D.S. (2013). Improving Situation Awareness to Reduce Unrecognized Clinical Deterioration and Serious Safety Events. Pediatrics, 131, e298.

Bruner, J. (1990). Acts of meanings. Cambridge, MA: Harvard University Press.

Bunge, M. \& R. Ardila (1987). Philosophy of psychology. New York: Springer-Verlag.

Cite as: Hudson AP, Duncan HP, Pattison HM, Shaw RL. Developing an intervention to equip nurses for Acute Life Threatening Events (ALTEs) in hospital: A phenomenological approach to healthcare research. Health Psychology 2015;34(4):361-370. Available from:

http://dx.doi.org/10.1037/hea0000193. 
Clohessy, S., \& Ehlers, A. (1999). PTSD symptoms, response to intrusive memories and coping in ambulance service workers. British Journal of Clinical Psychology, 38(Pt.3), 251265.

Carraccio, C. L., B. J. Benson, Nixon, L.J. \&Derstine, P.L. (2008). From the educational bench to the clinical bedside: translating the Dreyfus developmental model to the learning of clinical skills. Academic Medicine, 83, 761-767.

Cochrane (2011). Cochrane Handbook for Systematic Reviews of Interventions. Available from: http://handbook.cochrane.org/.

Cotterill-Walker, S. (2000). Debriefing in the intensive care unit: a personal experience of critical incident stress. Nursing in Critical Care, 5(2), 82-86.

Churchill, S. \& Wertz, F.J. (2001). An Introduction to Phenomenological Research in Psychology: Historical, Conceptual, and Methodological Foundations. In K.J. Schneider, J.F.T. Bugental \& J.F. Pierson (Eds.) The Handbook of Humanistic Psychology: leading edges in theory, research, and practice. Thousand Oaks, CA: Sage.

Crabbe, J. M., D. M. G. Bowley, et al. (2004). "Are health professionals getting caught in the corssfire? The personal implications of caring for trauma victims." Emergency Medicine Journal 21: 568-572.

Craig, P., Dieppe, P., MacIntyre, S., Michie, S., Nazareth, I. \& Petticrew, M. (2008). Developing and evaluating complex interventions: new guidance. Medical Research Council. Available from: $\underline{w w w . m r c . a c . u k / c o m p l e x i n t e r v e n t i o n s g u i d a n c e . ~}$

Dewey, J. (1933). How we think. Boston: D.C. Heath \& Co. for Acute Life Threatening Events (ALTEs) in hospital: A phenomenological approach to healthcare research. Health Psychology 2015;34(4):361-370. Available from: 
Dreyfus, S. E. (1982). "Formal models vs. human situational understanding: inherent limitations on the modelling of business expertise." Information Technology \& People, 1(2), $133-165$.

Dreyfus, H. \& Dreyfus, S. (1986). Mind over machine: the power of human intuitive expertise in the era of the computer. New York: Free Press.

Duncan, H., Hutchinson, J. \& Parshuram, C.S. (2006). The Pediatric Early Warning System score: a severity of illness score to predict urgent medical need in hospitalized children. Journal of Critical Care, 21(3), 271-278.

van Emmerik, A.A., Kamphuis, J.H., Hulsbosch, A.M., \& Emmelkamp, P.M. (2002). Single session debriefing after psychological trauma: a meta-analysis. The Lancet, 360, 766-771.

Everly, G. S. \& Mitchell, J. T. (1997). Critical Incident Stress Management (CISM):A New Era and Standard of Care in Crisis Intervention. Ellicott City: Chevron.

Finlay, L. (2003). Through the looking glass: intersubjectivity and hermeneutic reflection. In L. Finlay and B. Gough (Eds.) Reflexivity: a practical guide for researchers in health and social sciences. Oxford: Blackwell Publishing; pp. 103-119.

Ford, K., \& Turner, D.S. (2001). Stories seldom told: paediatric nurses' experiences of caring for hospitalized children with special needs and their families. Journal of Advanced Nursing, 33(3), 288-295.

Galvin, K. T. \& Todres, L. (2011). Research based empathetic knowledge for nursing: a translational strategy for disseminating phenomenological research findings to provide evidence for caring practice. International Journal of Nursing Studies, 48, 522-530. for Acute Life Threatening Events (ALTEs) in hospital: A phenomenological approach to healthcare research. Health Psychology 2015;34(4):361-370. Available from: 
Gamble, M. (2001). A debriefing approach to dealing with the stress of CPR attempts. Professional Nurse, 17(3), 157-160.

Haines, C., Perrott, M. \& Weir, P. (2006). Promoting care for acutely ill childrendevelopment and evaluation of a paediatric early warning tool. Intensive Critical Care Nursing, 22(2), 73-81.

Halpern, J., Gurevich, M., Schwartz, B., \& Brazeau, P. (2009). What makes an incident critical for ambulance workers? Emotional outcomes and implications for intervention. Work \& Stress, 23(2), 173-189.

Heiberg Engel, P. J. (2008). Tacit knowledge and visual expertise in medical diagnostic reasoning: implications for medical education. Medical Teacher, 30,184-188.

Hudson, A.P. (2014). Exploring the experiences of nurses who care for children who have acute life threatening events (ALTEs) in hospital. Unpublished doctoral thesis, Aston University, UK. Full text available online at http://eprints.aston.ac.uk/22689/ (last accessed $09 / 11 / 2014)$

Kolb, D. (1984). Experiential Learning: Experience as the Source of Learning and Development. Englewood Cliffs, NJ: Prentice Hall.

Leonhardt, J. \& J. Vogt (2006). Critical Incident Stress Management in Aviation. Ashgate Publishing.

Maslach, C. and S. E. Jackson (1980). "The measurement of experienced burnout." Journal of Occupational Behaviour 2: 99-113.

McCabe, A.P. \& Duncan, H. (2009). Paediatric early warning systems: where do we go from here? Paediatric Nursing, 21(1), 14-17.

Cite as: Hudson AP, Duncan HP, Pattison HM, Shaw RL. Developing an intervention to equip nurses for Acute Life Threatening Events (ALTEs) in hospital: A phenomenological approach to healthcare research. Health Psychology 2015;34(4):361-370. Available from:

http://dx.doi.org/10.1037/hea0000193. 
McInnes, B. \& C. Bannister (2002). RCN Working Well Initiative Guidance on traumatic stress management in the health care sector. London: Royal College of Nursing.

Mukherjee, S., B. Beresford, et al. (2009). "Burnout, psychiatric morbidity, and work-related sources of stress in paediatric oncology staff: a review of the literature." Psycho-Oncology 18: 1019-1028.

National Institute of Health Consensus Statement Online (1986). Infantile Apnea and Home Monitoring, 6, 1-10.

Nadkarni, V.M., Larkin, G.L., Peberdy, M.A. et al. (2006). First documented rhythm and clinical outcome from in-hospital cardiac arrest among children and adults. JAMA, 295(1), $50-57$.

Parker, P. and J. Kulik (1995). "Burnout, self- and supervisor-rated job performance, and absenteeism among nurses." Journal of Behavioural Medicine 18 (6): 581-599.

Pena, A. (2010). The Dreyfus model of clinical problem-solving skills acquisition: a crtical persepctive. Medical Education Online, 15, 1-11.

Pines, A. and C. Maslach (1978). "Characteristics of staff burnout in mental health settings." Hospital and Community Psychiatry 29(4): 233-237.

Pups, G., Weyker, J., Rodgers, B.L. (1997). Nurses' reactions to participation in cardiopulmonary resuscitation on the nursing unit. Clinical Nursing Research, 6(1), 59-70.

Rees, K. (2013). The role of reflective practices in enabling final year nursing students to respond to the distressing emotional challenges of nursing work. Nurse Education in Practice, 13, 48-52.

Cite as: Hudson AP, Duncan HP, Pattison HM, Shaw RL. Developing an intervention to equip nurses for Acute Life Threatening Events (ALTEs) in hospital: A phenomenological approach to healthcare research. Health Psychology 2015;34(4):361-370. Available from:

http://dx.doi.org/10.1037/hea0000193. 
Resuscitation Council (UK) Quality standards for cardiopulmonary resuscitation practice and training. November 2013. http://www.resus.org.uk/pages/QSCPR_Acute.htm\#research (last accessed 17/10/2014).

Rose, S., Bisson, J., Churchill, R., \& Wessely, S. (2002). Psychological debriefing for preventing post traumatic distress disorder. Cochrane Database Systematic Review, Issue 2, CD000560.

Rudolph, J.W., Simon, R., Dufresne, R.L. \& Raemer, D.B. (2006). There's no such thing as "nonjudgmental" debriefing: a theory and method for debriefing with good judgment.

Simulation Healthcare, 1(1), 49-55.

Scott, S.D., Hirschinger, L.E., Cox, K.R., McCoig, M., Brandt, J. \& Hall, L.W. (2009). The natural history of recovery for the healthcare provider "second victim" after adverse patient events. Quality \& Safety in Health Care, 18(5), 325-330.

Schaufeli, W. b., M. Salanova, et al. (2002). "The measurement of engagement and burnout: A two sample confirmatory factor analytic approach." Journal of Happiness Studies 3: 71-92.

Shaw, R. L. (2010). Embedding Reflexivity within Experiential Qualitative Psychology. Qualitative Research in Psychology 7(3), 233-243.

Smith, J.A. \& Eatough, V. (200). Interpretative phenomenological analysis. In G. Breakwell, J.A. Smith \& D.B. Wright (Eds.) Research methods in psychology (4 ${ }^{\text {th }}$ edition). London: Sage; pp.439-460.

Smith, J.A., Flowers, P. \& Larkin, M. (2009). Interpretative Phenomenological Analysis: theory, method and research. London: Sage. for Acute Life Threatening Events (ALTEs) in hospital: A phenomenological approach to healthcare research. Health Psychology 2015;34(4):361-370. Available from: 
Tibballs, J., Kinney, S., Duke, T., Oakley, E. \& Hennessy, M. (2005). Reduction of paediatric in-patient cardiac arrest and death with a medical emergency team: preliminary results. Archives of Diseases in Childhood, 90, 1148-1152.

Tiballs, J. \& Kinney, S. (2009). Reduction of hospital mortality and of preventable cardiac arrest and death on introduction of a paediatric medical emergency team. Paediatric Critical Medicine, 10(3), 306-312.

Tume, L. \& I. Bullock (2004). Early warning tool to identify children at risk of deterioration: a discussion. Paediatric Nursing, 16(8), 20-23.

van Wky, B.E., \& Pillay-Van Wky, V. (2010). Preventive staff-support interventions for health workers (review). The Cochrane Library, Issue 3. Available from:

http://onlinelibrary.wiley.com/doi/10.1002/14651858.CD003541.pub2/pdf/standard (last accessed 17/10/2014).

Willis, P. (2004). From “the things themselves" to "'a feeling of understanding": finding different voices in phenomenological research. Indo-Pacific Journal of Phenomenology, 4(1), $1-13$.

Yardley, L. (2000). Dilemmas in qualitative health research. Psychology \& Health, 15(2), 215-228.

Young, K. \& Seidel, J.S. (1999). Pediatric cardiopulmonary resuscitation: a collective review. Annals of Emergency Medicine, 33(2), 195-205.

Zigmond, A.S. \& Snaith, R.P. (1983). The hospital anxiety and depression scale. Acta Psychiatrica Scandinavica, 67(6), 361-370.

Cite as: Hudson AP, Duncan HP, Pattison HM, Shaw RL. Developing an intervention to equip nurses for Acute Life Threatening Events (ALTEs) in hospital: A phenomenological approach to healthcare research. Health Psychology 2015;34(4):361-370. Available from:

http://dx.doi.org/10.1037/hea0000193. 
Cite as: Hudson AP, Duncan HP, Pattison HM, Shaw RL. Developing an intervention to equip nurses for Acute Life Threatening Events (ALTEs) in hospital: A phenomenological approach to healthcare research. Health Psychology 2015;34(4):361-370. Available from:

http://dx.doi.org/10.1037/hea0000193. 
Table 1. Demographics of participants

\begin{tabular}{|l|l|l|l|l|l|}
\hline & $\begin{array}{l}\text { Years } \\
\text { experience }\end{array}$ & $\begin{array}{l}\text { Mean } \\
\text { years } \\
\text { experience }\end{array}$ & $\begin{array}{l}\text { Range of } \\
\text { years } \\
\text { experience }\end{array}$ & $\begin{array}{l}\text { Cardiac } \\
\text { arrest }\end{array}$ & $\begin{array}{l}\text { Urgent } \\
\text { Intensive } \\
\text { Care } \\
\text { admission }\end{array}$ \\
\hline Junior nurse (n=8) & 19.5 & 2.4 & $0.5-4$ & 5 & 2 \\
\hline Senior nurse $(\mathrm{n}=5)$ & 46 & 9.2 & $5-15$ & 4 & 1 \\
\hline Total nurses13 & 65 & 5 & $0.5-15$ & 9 & 3 \\
\hline Total doctors $(\mathrm{n}=11)$ & 104 & 9.5 & $3-20$ & 10 & 1 \\
\hline & & & & & \\
\hline
\end{tabular}

Cite as: Hudson AP, Duncan HP, Pattison HM, Shaw RL. Developing an intervention to equip nurses for Acute Life Threatening Events (ALTEs) in hospital: A phenomenological approach to healthcare research. Health Psychology 2015;34(4):361-370. Available from:

http://dx.doi.org/10.1037/hea0000193. 
Table 2: Synthesis of empirical and theoretical evidence to develop the intervention

\begin{tabular}{|c|c|c|c|c|}
\hline Elements of the intervention & IPA themes & Self-efficacy & $\begin{array}{l}\text { Reflective } \\
\text { thought }\end{array}$ & $\begin{array}{l}\text { Advocacy } \\
\text { Inquiry }\end{array}$ \\
\hline $\begin{array}{l}\text { Repeated exposure to ALTE environment: through } \\
\text { simulation the participants can witness and be involved } \\
\text { in the ALTE environment that will increase confidence } \\
\text { in their abilities and skills. }\end{array}$ & $\begin{array}{l}\text { Clinical } \\
\text { competence \& } \\
\text { confidence }\end{array}$ & $\begin{array}{l}\text { Modelling/vicarious } \\
\text { experience }\end{array}$ & $\begin{array}{l}\text { Developing a } \\
\text { sense of the } \\
\text { problem } \\
\text { Enriching the } \\
\text { sense with } \\
\text { relevant } \\
\text { observations }\end{array}$ & \\
\hline $\begin{array}{l}\text { Witnessing (role modelling) - scenario based } \\
\text { experiential learning provides the opportunity for } \\
\text { junior nurses to observe senior colleagues perform the } \\
\text { essential clinical skills required for resuscitation. } \\
\text { Experienced staff can role-model the particularly } \\
\text { challenging skills like drawing up medications and } \\
\text { supporting parents for their junior colleagues. }\end{array}$ & & $\begin{array}{l}\text { Modelling/vicarious } \\
\text { experience }\end{array}$ & & \\
\hline $\begin{array}{l}\text { Experience - nurses are not necessarily taught how to } \\
\text { perform all the essential clinical skills required for } \\
\text { resuscitation. Participation in a simulated ALTE } \\
\text { environment provides the opportunity for nurses to } \\
\text { witness the clinical skills and then practice them in a } \\
\text { safe environment. Participants in the IPA interviews } \\
\text { described feeling more confident and competent at } \\
\text { subsequent events if they have had the opportunity to } \\
\text { practice the skills during a previous ALTE. Allocation } \\
\text { of a role for the more junior nurses provides them with } \\
\text { purpose and helps to shift the focus from the person } \\
\text { within the patient to a clinical focus. Experience of } \\
\text { these events was good preparation for future events. }\end{array}$ & $\begin{array}{l}\text { Designated role } \\
\text { during } \\
\text { resuscitation } \\
\text { Misinterpreting } \\
\text { the stress } \\
\text { response }\end{array}$ & $\begin{array}{l}\text { Mastery/performance } \\
\text { Physiologically } \\
\text { compatible experience }\end{array}$ & $\begin{array}{l}\text { Enriching the } \\
\text { sense of the } \\
\text { problem with } \\
\text { relevant } \\
\text { observations }\end{array}$ & $\begin{array}{l}\text { Advocacy - } \\
\text { prompts the } \\
\text { description of an } \\
\text { experience }\end{array}$ \\
\hline Sense-making / reflection - the process of sense- & Sense-making \& & & Developing a & Inquiry - prompts \\
\hline
\end{tabular}

Cite as: Hudson AP, Duncan HP, Pattison HM, Shaw RL. Developing an intervention to equip nurses for Acute Life Threatening Events (ALTEs) in hospital: A phenomenological approach to healthcare research. Health Psychology 2015;34(4):361-370. Available from: http://dx.doi.org/10.1037/hea0000193. 


\begin{tabular}{|c|c|c|c|c|}
\hline $\begin{array}{l}\text { making and reflection needs to take place in order to } \\
\text { learn from each ALTE. That process permits } \\
\text { individuals to give the event context so the skills, } \\
\text { knowledge and experience can be drawn on for the } \\
\text { future. The process helps to move the parts of the event } \\
\text { from the unconscious to the conscious so they can be } \\
\text { accessed for future reference during subsequent ALTEs. } \\
\text { This can be facilitated through the provision of } \\
\text { feedback which provides an opportunity for people to } \\
\text { reflect on their own experience and that of others. } \\
\text { Junior colleagues will learn from senior colleagues (and } \\
\text { vice versa) as they go through a reflective process } \\
\text { together. }\end{array}$ & reflection & & $\begin{array}{l}\text { sense of the } \\
\text { problem }\end{array}$ & reflection \\
\hline $\begin{array}{l}\text { Consolidation - through consolidation the skills, } \\
\text { experience and knowledge gained at each event can be } \\
\text { added to at subsequent events. The participants are able } \\
\text { to perform the clinical skills more confidently and } \\
\text { competently which contributes to their experience. This } \\
\text { is a cyclical process - individuals will feel more } \\
\text { confident at subsequent events if they attend more } \\
\text { events and practice clinical skills. Consolidation can } \\
\text { only occur when the preceding processes (steps 1-4) } \\
\text { take place. }\end{array}$ & & $\begin{array}{l}\text { Mastery } \\
\text { experience/performance }\end{array}$ & $\begin{array}{l}\text { Test the } \\
\text { conclusion in } \\
\text { practice }\end{array}$ & \\
\hline
\end{tabular}

Cite as: Hudson AP, Duncan HP, Pattison HM, Shaw RL. Developing an intervention to equip nurses for Acute Life Threatening Events (ALTEs) in hospital: A phenomenological approach to healthcare research. Health Psychology 2015;34(4):361-370. Available from: http://dx.doi.org/10.1037/hea0000193. 


\section{Supplementary file 1: Systematic review search strategy}

1. (healthcare OR "health care" OR hospital*).af;

2. nurs*.af;

3. exp MEDICAL STAFF, HOSPITAL/ OR NURSING STAFF, HOSPITAL/;

4. 1 OR 2 OR 3;

5. ("cardiopulmonary arrest" OR "cardiac arrest" OR "cardio-pulmonary arrest" OR "cardio pulmonary

arrest" OR "CA").af;

6. ("cardiopulmonary resuscitation" OR "cardio-pulmonary resuscitation" OR "cardio pulmonary resuscitation" OR).af;

8. "acute deterioration".

9. exp HEART ARREST/

10 ("cardiorespiratory arrest" OR "cardio-respiratory arrest" OR "cardio respiratory arrest").af

11. ("cardiorespiratory resuscitation" OR "cardio-respiratory resuscitation" OR "cardio respiratory resuscitation").af

12. ("respiratory arrest" OR RA).af

13. ("peri-arrest" OR "peri arrest").af

14. ("acute life threatening event" OR "acute life threatening episode" OR ALTE).af

15. (("critical inciden*" NOT ("critical incident technique" OR "critical incident analysis" OR "critical incident report*" OR "critical incident interview*" OR "critical incident stud*"))).af

16. 6 OR 8 OR 9 OR 10 OR 11 OR 12 OR 13 OR 14 OR 15

17. exp STRESS DISORDERS, POST-TRAUMATIC/

18. ("post traumatic stress disorder" OR "post traumatic stress" OR "PTSD").af

Cite as: Hudson AP, Duncan HP, Pattison HM, Shaw RL. Developing an intervention to equip nurses for Acute Life Threatening Events (ALTEs) in hospital: A phenomenological approach to healthcare research. Health Psychology 2015;34(4):361-370. Available from:

http://dx.doi.org/10.1037/hea0000193. 
19. $\exp$ STRESS, PSYCHOLOGICAL/

20. "psychological stress".af;

21. BURNOUT, PROFESSIONAL/;

22. "burnout".af

23. ("occupation* stress" OR "occupation* health").af

24. distress.af

25. 17 OR 18 OR 19 OR 20 OR 21 OR 22 OR 23 OR 24

26. ("critical incident stress" OR "critical incident stress management" OR "CISM").af

27. ("critical incident stress debrief*" OR "CISD").af

28. "peer support".af

30. "crisis intervention".af

31. CRISIS INTERVENTION/

32. CRITICAL INCIDENT STRESS/ OR CRISIS INTERVENTION/ OR STRESS MANAGEMENT/

33. "stress management".af

34. "psychological support".af

35. ("manage*" OR "intervention*" OR "prepar*" OR "support*").af

36. 26 OR 27 OR 28 OR 30 OR 31 OR 32 OR 33 OR 34 OR 35

37. 4 AND 16 AND 25 AND 36

Cite as: Hudson AP, Duncan HP, Pattison HM, Shaw RL. Developing an intervention to equip nurses for Acute Life Threatening Events (ALTEs) in hospital: A phenomenological approach to healthcare research. Health Psychology 2015;34(4):361-370. Available from:

http://dx.doi.org/10.1037/hea0000193. 
Supplementary file 2: Demographics of the working party

\begin{tabular}{|l|}
\multicolumn{1}{|c|}{ Job role within the organisation } \\
\hline Experienced clinical nurse/facilitator of working party \\
\hline Paediatric intensive care consultant $x 2$ \\
\hline Education sister/experienced senior nurse \\
\hline Resuscitation services manager \\
\hline Clinical co-ordinator/experienced senior nurse \\
\hline Senior cardiac registrar \\
\hline Ward manager/experienced senior nurse \\
\hline Lead for clinical site practitioners \\
\hline Clinical site practitioner \\
\hline Band 6 nurse from paediatric intensive care \\
\hline Band 5 nurse from wards $x 3$ \\
\hline Band 6 nurse neonatal surgical ward \\
\hline Senior paediatric intensive care nurse and previous PEWS educator \\
\hline
\end{tabular}

Cite as: Hudson AP, Duncan HP, Pattison HM, Shaw RL. Developing an intervention to equip nurses for Acute Life Threatening Events (ALTEs) in hospital: A phenomenological approach to healthcare research. Health Psychology 2015;34(4):361-370. Available from:

http://dx.doi.org/10.1037/hea0000193. 